\title{
Blow-out limits of nonpremixed turbulent jet flames in a cross flow at atmospheric and sub-atmospheric pressures
}

\author{
Qiang Wang ${ }^{\mathrm{a}}$, Longhua $\mathrm{Hu}^{\mathrm{a}^{*}}$, Sung Hwan Yoon ${ }^{\mathrm{b}}$, Shouxiang $\mathrm{Lu}^{\mathrm{a}}$, \\ Michael Delichatsios ${ }^{c}$, Suk Ho Chung ${ }^{d}$
}

\author{
${ }^{\mathrm{a}}$ State Key Laboratory of Fire Science \\ University of Science and Technology of China \\ Hefei, Anhui, 230026, China \\ ${ }^{\mathrm{b}}$ Division of Mechanical and Space Engineering \\ Graduate School of Engineering \\ Hokkaido University \\ ${ }^{\mathrm{c}}$ FireSERT, School of Built Environment \\ University of Ulster \\ Newtownabbey BT38 8GQ, Ireland \\ ${ }^{\mathrm{d}}$ Clean Combustion Research Center \\ King Abdullah University of Science and Technology \\ Thuwal 23955-6900, Saudi Arabia
}

\footnotetext{
*Corresponding author: Tel: (86) 551 63606446; Fax: (86) 551 63601669; Email address:

hlh@ustc.edu.cn; Postal address: State Key Laboratory of Fire Science, University of Science and Technology of China, Hefei, Anhui, 230026, China
} 


\begin{tabular}{|c|c|c|c|}
\hline \multicolumn{4}{|c|}{ Nomenclature } \\
\hline$D$ & inner nozzle diameter $[\mathrm{mm}]$ & $u_{\infty}$ & velocity of cross flow $[\mathrm{m} / \mathrm{s}]$ \\
\hline$D a$ & Damköhler number & $x_{\mathrm{cr}}$ & $\begin{array}{l}\text { critical length of flame lift-off trajectory } \\
\text { line in cross direction }[\mathrm{m}]\end{array}$ \\
\hline$L_{\mathrm{cr}}$ & $\begin{array}{l}\text { critical length of flame lift-off trajectory line } \\
{[\mathrm{m}]}\end{array}$ & \multicolumn{2}{|c|}{ Greek symbols } \\
\hline$P_{\infty}$ & ambient pressure $[\mathrm{kPa}]$ & $\delta$ & local flame diameter \\
\hline$R$ & momentum ratio of fuel flow to cross flow & $\alpha$ & thermal diffusivity $\left[\mathrm{m}^{2} / \mathrm{s}\right]$ \\
\hline$s$ & the arch length of trajectory line $[\mathrm{m}]$ & $\rho_{\mathrm{e}}$ & fuel density $\left[\mathrm{kg} / \mathrm{m}^{3}\right]$ \\
\hline$S_{\mathrm{L}}$ & laminar burning velocity $[\mathrm{m} / \mathrm{s}]$ & $\rho_{\infty}$ & ambient air density $\left[\mathrm{kg} / \mathrm{m}^{3}\right]$ \\
\hline$T$ & temperature $[\mathrm{K}]$ & $\rho_{\mathrm{co}}$ & coflow air density $\left[\mathrm{kg} / \mathrm{m}^{3}\right]$ \\
\hline$u_{\mathrm{cl}}$ & local centerline velocity $[\mathrm{m} / \mathrm{s}]$ & $\theta$ & angle between flame body and jet direction \\
\hline$\tilde{u}_{\mathrm{c}}$ & effective velocity for flame in cross flow $[\mathrm{m} / \mathrm{s}]$ & $\tau_{\mathrm{m}}$ & mixing time in Eq. (1a) \\
\hline$u_{\mathrm{co}}$ & coflow velocity $[\mathrm{m} / \mathrm{s}]$ & $\tau_{\mathrm{c}}$ & chemical reaction time in Eq. (1a) \\
\hline$u_{\mathrm{c}, \mathrm{x}}$ & local centerline velocity in cross direction $[\mathrm{m} / \mathrm{s}]$ & \multicolumn{2}{|c|}{ Subscripts } \\
\hline$u_{c, y}$ & local centerline velocity in jet direction $[\mathrm{m} / \mathrm{s}]$ & $\infty$ & ambient \\
\hline$u_{\mathrm{e}}$ & velocity of fuel ejected from nozzle $[\mathrm{m} / \mathrm{s}]$ & e & fuel \\
\hline$u_{\text {eff }}$ & effective velocity for coflow flame $[\mathrm{m} / \mathrm{s}]$ & & \\
\hline
\end{tabular}




\section{Abstract}

The blow-out limits of nonpremixed turbulent jet flames in cross flows were studied, especially concerning the effect of ambient pressure, by conducting experiments at atmospheric and sub-atmospheric pressures. The combined effects of air flow and pressure were investigated by a series of experiments conducted in a specially built wind tunnel in Lhasa, a city on the Tibetan plateau where the altitude is $3650 \mathrm{~m}$ and the atmospheric pressure condition is naturally low (64 $\mathrm{kPa}$ ). These results were compared with results from a wind tunnel under standard atmospheric pressure $(100 \mathrm{kPa})$ in Hefei city (altitude $50 \mathrm{~m})$. The size of the fuel nozzles used in the experiments ranged from 3 to $8 \mathrm{~mm}$ in diameter and propane was used as the fuel. It was found that the blow-out limit first increased and then decreased as the fuel jet velocity increased in both pressures, however, the blow-out limit of the air speed of the cross flow was much lower under the sub-atmospheric pressure than that under standard atmospheric pressure with the domain of the blow-out limit in a plot of the air speed of the cross flow in relation to the fuel jet velocity shrank as the pressure decreased. A theoretical model was developed to characterize the blow-out limit of nonpremixed jet flames in a cross flow based on a Damköhler number, defined as the ratio between the mixing time and the characteristic reaction time. A satisfactory correlation was obtained that included the effects of the air speed of the crossflow, fuel jet velocity, nozzle diameter and pressure.

\section{Keywords}

Nonpremixed turbulent jet flame; cross flow; blow-out limit; pressure effect. 


\section{Introduction}

Flame stabilization of nonpremixed turbulent jet flames has been studied extensively because of the fundamental importance of understanding physical mechanisms as well as because of the importance of flame stabilization to burner design. Lift-off heights and blow-out limits are important parameters in characterizing nonpremixed jet flame stability. Even under quiescent air conditions [1], the stabilization of the blow-out is quite complex. Much research has been conducted to interpret this behavior with several controlling mechanisms proposed [2-5]. Kalghatgi [4] developed a premixed flame model and successfully quantified the blow-out stability limit of gaseous jet diffusion flames in quiescent air with a universal non-dimensional formula. Broadwell et al. [5] proposed a large-scale mixing model and defined as a criterion of the ratio between the chemical reaction time and the turbulent mixing time to characterize the stability of turbulent diffusion flames. The effect of coflow air on the blow-out limit was also investigated [6-15] and an effective velocity was proposed. The effect of coflow air temperature was also studied $[16,17]$.

In contrast, although the flame stabilization of nonpremixed jet flames in cross flows is practically important to combustor burners [18] as well as to flares employed for emergency venting and gas separation of petrochemical and refinery stacks [19], studies of the blow-out limit in cross flows are rather limited. Any cross flow makes the flame stabilization of nonpremixed jet flames much more complicated by influencing turbulent mixing. As a consequence, quantifying flame stabilization of nonpremixed jet flames in cross flow is very difficult. Previously, Kalghatgi [20] proposed a widely applied empirical blow-out limit curve $\left(u_{\infty} / D\right.$ vs $\left.u_{\mathrm{e}} / D\right)$, where $u_{0}$ and $u_{\mathrm{e}}$ are the velocities of the cross flow air and fuel jet, respectively, and $D$ is the nozzle diameter. The blow-out phenomenon was further discussed by Lee and Shin [21] and direct numerical simulations 
(DNS) of flame stabilization and blowout in a nitrogen-diluted hydrogen transverse jet were conducted by Chen and coworkers [22-24]. However, a theoretical model is still needed to describe the blow-out limits of nonpremixed turbulent jet flames in cross flows.

Concerning the pressure effect, there has been no published study on blow-out limits with cross flows especially under the sub-atmospheric pressure condition, although such a condition is realistic, for example, at high-altitude locations. Recently, several experiments [25-27] were carried out in Lhasa, a city on the Tibetan plateau (altitude $3650 \mathrm{~m}$; pressure $64 \mathrm{kPa}$ ). Combustion behaviors, including lift-off [27], were found to differ appreciably from those under standard atmospheric pressure $(100 \mathrm{kPa})$. The blow-out limits with cross flows under sub-atmospheric pressure are important and crucial to the design and use of diffusion jet burners and flares in high altitude regions

In this study, experiments were carried out using a specially built wind tunnel in Lhasa where the atmospheric pressure is naturally low. Results from these experiments were compared with those from a wind tunnel in Hefei, where the atmospheric pressure is standard to evaluate the effect of pressure on blow-out limits in cross flows. A theoretical model was also developed to interpret blow-out limit behaviors when the air speed of the cross flow as well as the ambient pressure were varied.

\section{Experiment}

A wind tunnel was built in Lhasa, Tibet (altitude $3650 \mathrm{~m}$ ) where the ambient pressure is $P_{\infty}=64$ $\mathrm{kPa}$. The cross-section of the wind tunnel is $1.5 \mathrm{~m}$ in height and $1.2 \mathrm{~m}$ in width and its length is $10 \mathrm{~m}$, as schematically shown in Figure 1. In the tunnel, the cross flow air is generated by a mechanical fan installed at one end. A honeycomb is also installed in the tunnel for flow stabilization. The other end 
of the tunnel is open. The air speed was controlled ranging from 0 to $4.5 \mathrm{~m} / \mathrm{s}$ at designed levels (with its mean profile exposed to the flame changed at intervals of about $0.1 \mathrm{~m} / \mathrm{s}$ from case to case) and monitored by a hot-wire anemometer. Fuel jet nozzles with the inner diameters of 3 to $8 \mathrm{~mm}$ and wall thicknesses of about $1.5 \mathrm{~mm}$ were placed $0.5 \mathrm{~m}$ from the exit of the wind tunnel. The fuel nozzle exit was located $0.3 \mathrm{~m}$ above the bottom level of the wind tunnel. The fuel was propane and the flow rate was regulated by a gas flow rate meter. Corresponding experiments under normal atmospheric pressure were conducted in a wind tunnel in Hefei (altitude $50 \mathrm{~m} ; P_{\infty}=100 \mathrm{kPa}$ ). The air speed is also ranging from 0 to $4.5 \mathrm{~m} / \mathrm{s}$ with the same intervals. The details of this wind tunnel were described previously [28]. The ambient temperature is around $291 \mathrm{~K}$ in Lhasa and $293 \mathrm{~K}$ in Hefei, respectively. And the fuel temperature at the outlet of the nozzle is close to the environment according to our measurement. The flames were recorded by a CCD camera. All experiments were repeated three times.

\section{Results and Discussion}

\subsection{Flame evolution and blow-out limit}

Figure 2 shows photos of nonpremixed turbulent jet flames that exhibit typical variations in shape when subjected to cross flows with increasing air speed, $u_{\infty}$. At a fixed fuel jet velocity of $u_{\mathrm{e}}=$ $39.3 \mathrm{~m} / \mathrm{s}$ for $D=3 \mathrm{~mm}$ and $P_{\infty}=100 \mathrm{kPa}$ (a), the flame is lifted even without the cross flow with a lift-off height of $7.2 \mathrm{~cm}$. This lifted flame behavior with cross flow is therefore different in nature from a "wake-stabilized flame" [29] in which the flame is stabilized in the near-nozzle wake region when the momentum flux ratio of the fuel jet to the air stream is small.

The result shows that there are three regimes depending on the air speed. For $u_{\infty}$, up to $\sim 2.0 \mathrm{~m} / \mathrm{s}$, 
the degree of bending of the flame becomes more pronounced with increasing air speed. Simultaneously, the flame height and length decrease and the blue flame region enlarges. This can be attributed to enhanced air entrainment and mixing into the fuel region with $u_{\infty}$ in the region between the nozzle and the lifted flame edge, leading to stronger partial premixing in the fuel core. Consequently, the overall flame becomes less luminous.

As the air speed increases (to $\sim 3.0 \mathrm{~m} / \mathrm{s}$ ), the overall flame shape does not change much and the main flame body tends to be nearly parallel to the cross flow direction. The flame edge, which has a nearly vertical shape, moves toward the downstream of the air flow. The flame becomes bluer and much less luminous, while it also becomes elongated to some extent in the horizontal direction.

As the air speed increases further to an excessive level (over $\sim 3.0 \mathrm{~m} / \mathrm{s}$ ), a stable flame cannot be sustained. The flame transits from a lifted stable flame to extinction process. Similar to the process observed by Moore [13] in co-flow condition, when the cross flow increases to a level excessing a threshold of blow-out value, the flame transits from a lifted stable flame to instable condition. The leading-edge of the flame front moves downstream with the shrinking of its flame area gradually. Meanwhile, the trailing diffusion flame has also been significantly reduced in the recession process. The whole flame ends with the disappearance of the leading edge and a blow-out occurs. As exemplified in Fig. 2(a), in the process of increasing the cross flow velocity to next level gradually, a blow-out occurs at $u_{\infty}=3.37 \mathrm{~m} / \mathrm{s}$ (real-time value monitored by the anemometer; when reaching the blow-out case, the time for flame blow out (the time taken for the leading-edge of the flame front moves downstream to finally blow-out) is in fact very short (less than 1 second)). The last four photos in Fig. 2(a) show the evolution of flame during the blow-out process with a time interval of $0.04 \mathrm{~s}$. At $u_{\infty}=3.30 \mathrm{~m} / \mathrm{s}$, the flame is sustained for over $3 \mathrm{~min}$ (we wait for 3 minutes to 
assure that the flame is not blown-out in one case to avoid uncertainty due to the fluctuation of the flame itself in the cross flow). The critical cross flow speed at blow-out is defined as when the flame cannot sustain and blow-out occurs; it is thus $3.37 \mathrm{~m} / \mathrm{s}$ for this case.

A similar three-regime behavior can also be seen under the sub-atmospheric pressure (64 $\mathrm{kPa})$ condition for $u_{\mathrm{e}}=16.9 \mathrm{~m} / \mathrm{s}$ as shown in Fig. 2(b). Figure 2(c) shows the close-up photos near the lifted flame edges. There is an appreciable difference in lift-off heights between the windward side and the lee side, which can be attributed to different mixing strengths on the two sides. Physically, the flow field of a jet flame in the cross flow is more complicated than that of a free jet flame in quiescent air because of the interaction of fuel jet and cross flow. In a cross flow, the flame edge at the upper windward side could experience a relatively higher strain effect because of positive strain in the transverse direction as compared with the lee side.

The blow-out limit in terms of the air speed of the cross flow versus the fuel jet velocity is plotted in Fig. 3. The result shows that for $P_{\infty}=100 \mathrm{kPa}$, the air speed at the blow-out limit increases reasonably linearly with the fuel jet velocity, while for $P_{\infty}=64 \mathrm{kPa}$, it increases with fuel jet velocity and then decreases.

To examine this nonlinear behavior, the data are plotted with the velocities scaled with the nozzle diameter in Fig. 4 along with the data by Kalghatgi [20] in normal pressure $\left(P_{\infty}=100 \mathrm{kPa}\right)$, which can be found in the literatures concerning the topic of blow-out for propane fuel in cross flow with the nozzle diameters in the range of $4-14 \mathrm{~mm}$, the fuel jet velocities ranging from 20 to 250 $\mathrm{m} / \mathrm{s}$, and the cross flow speed ranging from 0 to $8 \mathrm{~m} / \mathrm{s}$ at the normal pressure $(100 \mathrm{kPa})$. The result shows that the present data at $P_{\infty}=100 \mathrm{kPa}$ and the previous ones [20] are consistent.

Both the cases with $P_{\infty}=100$ and $64 \mathrm{kPa}$ show nonlinear behavior. Two regimes, the "cross 
flow dominant" regime for relatively low fuel jet velocities and the "fuel jet dominant" regime for relatively high fuel jet velocities, have been identified [20] (which is more clearly shown for the data of $P_{\infty}=100 \mathrm{kPa}$; meanwhile for the data of sub-atmospheric pressure $\left(P_{\infty}=64 \mathrm{kPa}\right)$, the turning point for these two regimes are not very clear due to limited data at very high fuel jet velocity condition that we could not accurately label it, however it is convinced that the data should be mainly locates in "cross flow dominant" regime). The variation trend of blow-out cross flow speed with fuel jet velocity is completely different in these two regimes, indicating the change of the dominant mechanism. In the cross flow dominant regime, blow-out should be mainly induced by the strain effect generated by the cross flow. In this case, firstly, the flame should be blown to be nearly horizontal by the cross flow (in this stage, higher cross flow is needed at larger fuel jet velocity to change the flame to be mainly horizontal). And then, the flame is blow-out by the cross flow along the horizontal direction. Consequently, the critical air speed of the cross flow at blow-out increases with fuel jet velocity until point $\mathrm{A}$, where the jet fuel velocity reaches close to the value of the self-blow-out limit in quiescent air (corresponding to point $\mathrm{C}$ where the air speed of the cross flow is zero). After point A, since the fuel jet velocity is above the value of the self-blow-out limit under quiescent conditions, there is a shift to the fuel jet dominant regime. That is, the flame blow-out is mainly induced by the strain generated by the high-speed fuel jet itself. With the increase in the fuel jet velocity, the flame is more strained and thus requires less aid from the cross flow to reach the blow-out limit, such that the critical air speed of the cross flow at blow-out decreases with the fuel jet velocity until its maximum value for a sustainable flame at point B. Note that the critical blow-out jet fuel velocity at point B is higher than that in quiescent air (point C). This is because the cross flow enhances the turbulent mixing of the surrounding air into the fuel jet, which decreases the jet fuel 
velocity as does the strain rate along the trajectory line. The flame cannot be sustained when the jet fuel velocity is above that in "point B" even in the cross flow. To have a sustained flame, the fuel jet velocity has to be decreased and then the critical air speed of the cross flow at blow-out also decreases correspondingly (from point B to C) and finally becomes zero at the self-blow-out condition (point $\mathrm{C}$, where the blow-out is solely induced by the strain effect generated by the strong fuel jet itself). These behaviors form a blow-out limit curve (or a stabilization domain enveloped by the curve).

As the ambient pressure decreases to $P_{\infty}=64 \mathrm{kPa}$, the blow-out limit curve shrinks appreciably as compared with the case for $P_{\infty}=100 \mathrm{kPa}$, implying that the flame is much more susceptible to blow-out as the ambient pressure decreases in terms of the fuel jet and cross flow velocities. The local maximum, $u_{\infty} / D$, at blow-out in this sub-atmospheric pressure condition decreases to about $400 \mathrm{~s}^{-1}$, which is about one-third of that in the standard atmospheric pressure condition of about 1200 $\mathrm{s}^{-1}$. The corresponding $u_{\mathrm{e}} / D$ also decreases. It should be noted that the model proposed by Kalghatgi [20] does not include the effect of pressure. As such, a more general physical model is needed to understand the blow-out limit while also taking into account the pressure effect.

\subsection{A physical model based on the Damköhler number}

A schematic of the proposed model is shown in Fig. 5. In a cross flow, the flame is bent and a trajectory line can be traced that originates from the center of the jet exit [30-31] (the inset represents a co-flow flame configuration to determine a characteristic velocity, which is discussed below). At blow-out, the edge flame can be extinguished at an excessive strain rate or in terms of the Damköhler number, $D a$, which can be defined as the ratio between the mixing time, $\tau_{\mathrm{m}}$, and the characteristic reaction time, $\tau_{\mathrm{c}}$, similar to the proposal for the case without cross flow by Broadwell [4]. The 
mixing time can be defined as $L / u$, where $L$ is the mixing length and $u$ is the characteristic velocity to be defined later. The characteristic reaction time can be defined as $\alpha / S_{\mathrm{L}}^{2}$, where $\alpha$ is the thermal diffusivity ( $\alpha=\lambda / \rho c_{\mathrm{p}}$, where $\lambda$ is the thermal conductivity, $\rho$ is the density, and $c_{p}$ is the specific heat at constant pressure) and $S_{\mathrm{L}}$ is the laminar burning velocity, which has a pressure dependence [32-34]. Then, the Damköhler number becomes:

$$
D a \equiv \frac{\tau_{m}}{\tau_{c}}=\frac{L / u}{\alpha / S_{L}^{2}}
$$

which can be rearranged as

$$
u \sim L \frac{S_{L}^{2}}{\alpha D a}
$$

There are two values, $L$ and $u$, that need to be quantified for the blow-out condition in cross flows. The critical $D a$ is nearly constant for a jet without cross flow (5.6 for propane in Broadwell [4]). This constant critical $D a$ with cross flow is discussed below.

For the characteristic velocity at blow-out, the flame edge is almost parallel to the cross flow direction with the tilting angle, $\theta$, from the jet axis close to $90^{\circ}$ (Fig. 5). In such a case, the flow configuration of a nearly horizontal flame with cross flow may be regarded as a co-flow flame [35] (similar to the inset in Fig. 5). This assumption also comes from the physical fact the blow-out process observed is also similar to that reported by Moore [13] in co-flow condition as described in section 3.1. However, it should be noted that this assumption will be more satisfied with strong cross flow (for example, prior to "A" point in Fig. 4, where the flame has a relative large angle $\theta$ [close to $90^{\circ}$ f from the jet direction, and the blow-out is mainly dominated by the cross flow). It was reported that the effective velocity [6-8], which combines the effects from the fuel jet and the co-flow, can be calculated as 


$$
u_{\mathrm{eff}}=u_{\mathrm{e}}+C \sqrt{\rho_{\mathrm{e}} / \rho_{\mathrm{co}}} u_{\mathrm{co}}
$$

where $C$ is a constant of $40[6-8]$.

Similarly, with cross flow, the effective velocity can be defined as

$$
\tilde{u}_{\mathrm{c}}=u_{\mathrm{c}}+C \sqrt{\rho_{\mathrm{e}} / \rho_{\infty}} u_{\infty} \sin \theta
$$

where $u_{\mathrm{c}}$ is the local centerline velocity (fuel partially mixed with entrained air) and the value of sin, $\theta$, is close to 1 .

The local centerline velocity, $u_{\mathrm{c}}$, can be determined based on the centerline velocity profile in jet flames with cross flow proposed by Hasselbrink [36]. It was reported [e.g., 36] that the scaling law of the velocity profile was represented with the momentum ratio, $R$, between the fuel jet flow and the cross flow air as $R=\left(\frac{\rho_{\mathrm{e}} u_{\mathrm{e}}^{2}}{\rho_{\infty} u_{\infty}^{2}}\right)^{1 / 2}$ in the far-field region $((y / D) / R>>1)$, where the horizontal and vertical velocity components, $u_{\mathrm{c}, \mathrm{x}}$ and $u_{\mathrm{c}, \mathrm{y}}$, approach $u_{\infty}$ and 0 , respectively. The centerline velocity in the $x$ and $y$ directions are expressed as:

$$
\begin{gathered}
\frac{u_{\infty}-u_{\mathrm{c}, \mathrm{x}}}{u_{\infty}}=\frac{c_{\mathrm{vf}}}{\left(9 c_{\mathrm{ew}}\right)^{1 / 3}} \frac{1}{R}\left(\frac{\rho_{\mathrm{e}}}{\rho_{\infty}}\right)^{1 / 2}\left(\frac{x}{R D}\right)^{-2 / 3} \quad(x \text {-direction); } \\
\frac{u_{\mathrm{c}, \mathrm{y}}}{u_{\mathrm{e}}}=\frac{c_{\mathrm{uf}}}{\left(9 c_{\mathrm{ew}}\right)^{1 / 3}} \frac{1}{R}\left(\frac{\rho_{\mathrm{e}}}{\rho_{\infty}}\right)^{1 / 2}\left(\frac{x}{R D}\right)^{-2 / 3} \quad \text { (y-direction) }
\end{gathered}
$$

Here, the entrainment coefficients are $c_{\mathrm{vf}} \approx 2.0, \frac{c_{\mathrm{uf}}}{\left(9 c_{\mathrm{ew}}\right)^{1 / 3}}=1.1$ and $c_{\mathrm{ew}}=0.32 \sim 0.73$ with $c_{\mathrm{ew}} \approx 0.73$ in the far-field [36]. Then, the local fuel velocity at the centerline can be calculated from

$$
u_{\mathrm{c}}=\sqrt{u_{\mathrm{c}, \mathrm{x}}^{2}+u_{\mathrm{c}, \mathrm{y}}^{2}}
$$

Based on Eqs. (3b) and (5), a blow-out could occur when either the fuel jet velocity or the air speed of the cross flow becomes excessive, which is physically in accordance with the observations in Fig. 3 and Fig. 4 in the "cross flow dominant" or the "fuel jet dominant" regime. 
The length scale, $L$, in the Damköhler number definition can be the critical length, $L_{\mathrm{cr}}$, of the flame trajectory line in the last stable condition. The arch length has been calculated based on its coordinate $(x, y)$ equation for the trajectory line, which is based on the momentum ratio $(R)$ between the fuel jet and the cross air flow, proposed in [30-31]:

The trajectory (arch) line coordinate $(x, y)$ equation is provided in [30-31]

$$
\frac{y}{R D}=A\left(\frac{x}{R D}\right)^{B}
$$

where $R$ is momentum ratio of fuel flow to cross flow, $D$ is nozzle diameter; $A$ and $B$ are constants and their values are reported in the literature [31] in the range of $1.2<\mathrm{A}<2.6$ (its exact value is solved for each case based on its blow-out point coordinates $(x, y)$ which we can know from the experiments), and $B=1 / 3$. As all these parameters are independent of pressure, we can assume that this equation is applicable in both pressures.

Then, the trajectory (arch) line length $(s)$ [31] from its origin at any horizontal distance, $x$, can be calculated by the following integration:

$$
s=\int_{0}^{s} d s=\int_{0}^{x}\left[\left(\frac{d y^{2}}{d x^{2}}+1\right)+1\right]^{1 / 2} d x
$$

Its corresponding value at critical blow-out condition (the critical horizontal distance $x_{c r}$ can be measured from the experiments) is found as the length scale, $L_{c r}$ :

$$
L_{c r}=\left.s\right|_{x=x_{c r}}=\int_{0}^{x_{c r}}\left[\left(\frac{d y^{2}}{d x^{2}}+1\right)+1\right]^{1 / 2} d x
$$

Note that the values of $x_{\mathrm{cr}}$ (in Fig. 5) and corresponding $L_{\mathrm{cr}}$ are larger under sub-atmospheric pressure than that under normal pressure at the same velocity conditions.

The measured value of the length scale, $L_{\mathrm{cr}}$, from the experiments was non-dimensionalized by the length scale of $u_{\mathrm{e}} \tau_{\mathrm{c}}$. The values of $\alpha$ and $S_{\mathrm{L}}$ under standard pressure were adopted from [4]. The 
value of $\alpha$ under sub-atmospheric pressure can be calculated based on the ambient density change with pressure. And the relative change of $S_{\mathrm{L}}$ with pressure can be calculated based on its pressure dependence, $S_{\mathrm{L}} \propto P_{\infty}^{(n-2) / 2}$, in which the overall reaction order, $n$, can be specified as a global value for a given fuel (1.75 for propane [32] used here), which is applicable in a range of ambient pressures [32, 37-39]. Note that $L_{\mathrm{cr}}$ without cross flow (quiescent air) is in fact the critical lift-off length, which is proportional to $u_{\mathrm{e}} \tau_{\mathrm{c}}[5]$. Thus, the normalized value, $\frac{L_{\mathrm{cr}}}{u_{\mathrm{e}} \tau_{\mathrm{c}}}$, can be regarded as the ratio of the lift-off length in the cross flow to that without cross flow at the blow-out condition.

This non-dimensionalized length scale, $\frac{L_{\mathrm{cr}}}{u_{\mathrm{e}} \tau_{\mathrm{c}}}$, is plotted against the inverse of the momentum ratio between the fuel jet and cross air flow, $1 / R$, in Fig. 6. In the case without cross flow, $\frac{L_{\mathrm{cr}}}{u_{\mathrm{e}} \tau_{\mathrm{c}}}$ should approach the value of about 2.04, as reported previously in quiescent air [5]. The result shows that the critical length linearly correlates well with the momentum ratio for both the atmospheric and sub-atmospheric pressures as

$$
L_{\mathrm{cr}}=u_{\mathrm{e}} \tau_{\mathrm{c}}\left(2.04+\frac{143.5}{R}\right)
$$

The Damköhler number concept for blow-out in cross flow is tested by determining the critical characteristic velocity, $\tilde{u}_{\mathrm{c}}$, calculated from Eqs. (3b) and (5), as well as the characteristic length from Eq. (8), We have plotted $\tilde{u}_{\mathrm{c}}$ in relation to $\frac{L_{\mathrm{cr}} S_{\mathrm{L}}^{2}}{\alpha D a}$ in Fig. 7 using the same critical Damköhler number reported previously as 5.6 for propane for the case without cross flow [4]. The data of Kalghatgi [20], which we can only find in the literatures on this topic in normal pressure, are also included (their corresponding value of $L_{c r}$ are calculated from our proposed relation (Eq. 8) as the values of $x_{c r}$ were not provided in [20] that $L_{c r}$ cannot be integrated from Eq. (7)). It is noted that, as 
indicated in Fig.4, the data of Kalghatgi covers both "cross flow dominant" and "fuel jet dominant" regime, while the data in this work mainly locates in "cross flow dominant" regime (both in normal pressure and sub-atmospheric pressure). We can make following observations regarding to Fig.7:

(1) Generally, the data of Kalghatgi converges well with our data following the linear correlation, especially for the data at the "cross flow dominant" regime (prior to "A" point in Fig.4, with relative large angle $\theta$ close to 90 degrees regarding definition in Fig.5), however;

(2) For the "fuel jet dominant" regime (beyond to "A" point in Fig.4), the data seems to some deviate from the linear trend line. This is due to that in "fuel jet dominant" regime, the flame will be less bended at relative lower cross flow compared with the strength of the fuel jet (with relative small angle $\theta$ which should be some smaller than 90 degrees; however, as we do not know the exact value of this angle for the data of Kalghatgi, we have to assume its $\sin (\theta)$ to be 1 as we do for the "cross flow dominant" regime, which will make the deduced value of $\tilde{u}_{c}$ to be some higher than is real value, , as indicated by Eq. (3b)). So, in the "fuel jet dominant" regime, the basic "co-flow assumption" with $\sin (\theta)$ to be 1 is less satisfied in this condition. Concerning the extreme condition with no cross flow (completely fuel jet dominant), the "co-flow assumption" model proposed in this paper should be not applicable any more.

So, we must address and clarify that the proposed correlation should be more convincing for application in the "cross flow dominant" regime at relative strong cross flow condition. As shown in Fig.7, all the data in the "cross flow dominant" regime of Kalghatgi [20] and of this work can be well converged and correlated by the following linear relation for both atmospheric and sub-atmospheric pressures and for various nozzle diameters:

$$
\tilde{u}_{\mathrm{c}}=1.74 \frac{L_{\mathrm{cr}} S_{\mathrm{L}}^{2}}{\alpha D a}
$$


This implies that the model is unified in interpreting the blow-out behavior of the fuel jet both in quiescent air and with cross flow including pressure effects, since the same critical Damköhler number (5.6) has been used. When substituting Eq. (8) into Eq. (9a) with $\tau_{\mathrm{c}}=\alpha / S_{\mathrm{L}}^{2}$, it becomes:

$$
\tilde{u}_{\mathrm{c}} \propto \frac{u_{\mathrm{e}}\left(2.04+\frac{143.5}{R}\right)}{D a}
$$

with constant $D a$. This relation is independent of the pressure and flow configuration. It can thus be a practical and useful formula in correlating the blow-out limit for various diameters and pressures. This relation also means for a given $u_{e}$, the critical effective velocity, $\tilde{u}_{\mathrm{c}}$, is same for different pressures (as $D a$ is constant and independent of pressure). However, $\tilde{u}_{\mathrm{c}}$ is reached by the combining effects from fuel jet velocity, $u_{e}$, and cross flow, $u_{\infty}$, along the trajectory line, $L$. In the sub-pressure atmosphere, the critical $L_{c r}$ or the value of $x_{c r}$ is larger, as the characteristic reaction time, $\tau_{\mathrm{c}}\left(=\alpha / S_{L}^{2}\right)$ is dependent of pressure due to the change of the laminar flame speed with pressure (this is also why even in no cross flow condition, the lift-off height is higher in the sub-atmospheric pressure than that in normal pressure as shown in [27], which is due to the larger value of $\tau_{\mathrm{c}}$ in the sub-atmospheric pressure). This means for a same fuel jet velocity, $u_{e}$, the value of RHS (Right Hand Side) of Eq. (4a) is relatively smaller (or the ratio $u_{\mathrm{c}, \mathrm{x}} / u_{\infty}=1-\frac{c_{\mathrm{vf}}}{\left(9 c_{\mathrm{ew}}\right)^{1 / 3}} \frac{1}{R}\left(\frac{\rho_{\mathrm{e}}}{\rho_{\infty}}\right)^{1 / 2}\left(\frac{x}{R D}\right)^{-2 / 3}$ is larger) with larger $x_{c r}$ in the sub-atmospheric pressure than that in normal pressure (note that in the blow-out case the flame is nearly parallel to the cross flow and $u_{c}$ is mainly determined by the value of $u_{c, x}$, meanwhile $u_{c, y}$ is small and negligible). Then, according to Eq. (3a) (Eq. 3a can be further arranged as $\left.\tilde{u}_{\mathrm{c}}=u_{\infty} \cdot\left[1-\frac{c_{\mathrm{vf}}}{\left(9 c_{\mathrm{ew}}\right)^{1 / 3}} \frac{1}{R}\left(\frac{\rho_{\mathrm{e}}}{\rho_{\infty}}\right)^{1 / 2}\left(\frac{x}{R D}\right)^{-2 / 3}+C \sqrt{\rho_{\mathrm{e}} / \rho_{\infty}} \sin \theta\right]\right)$, for a same $\tilde{u}_{\mathrm{c}}$, the critical value of $u_{\infty}$ should be relatively smaller in the sub-atmospheric pressure as the value in the bracket is 
relatively larger. So, the pressure effect is in fact imbedded in the parameter-effective velocity, $\tilde{u}_{\mathrm{c}}$ with different values of critical trajectory line (lift-off) length, $L$, or more basically due to physically the difference of laminar flame speeds in different pressures.

\section{Concluding remarks}

This paper presents an experiment investigation of blow-out behaviors of turbulent jet diffusion flames with the combined effects of cross flow and atmospheric pressure, for which no data were available in the past. A physical global model is proposed to describe the evolution of the blow-out limit with cross flow in different ambient pressures. Major findings include:

The air speed with cross flow at the blow-out limit is much lower in a sub-atmospheric pressure $(64 \mathrm{kPa})$ environment than it is in a normal pressure $(100 \mathrm{kPa})$ environment; the blow-out air speed first increases and then decreases as the fuel velocity increases. The blow-out limit curve (or the stabilization domain enveloped by this curve) shrinks as the ambient atmospheric pressure decreases.

A theoretical model that characterizes the blow-out limit of jet diffusion flame in cross flow based on the Damköhler number is developed. Considering proper definitions of length and velocity scales, all the experimental data can be collapsed into a single linear relation irrespective of the nozzle diameter and pressure condition.

\section{Acknowledgement}

This work was supported by the Excellent Young Scientist Fund of National Natural Science Foundation of China (Grant No. 51422606) and NSFC-RS Newton Advanced Fellowship (Grant No. 5141101261) to Longhua $\mathrm{Hu}$, the National Basic Research Program of China (Grant No. 
2012CB719702), and Fundamental Research Funds for the Central Universities. Suk Ho Chung was supported by KAUST.

\section{References}

[1] M.A. Delichatsios, GH. Markstein, L. Orloff, J. de Ris, Gas Research Institute, 1987, GRI 5085-260-1137.

[2] L. Vanquickenborne, A. Van Tiggelen, Combust. Flame 10 (1) (1966) 59-69.

[3] S.H. Chung, Proc. Combust. Inst. 31 (1) (2007) 877-892.

[4] J. E. Broadwell, W. J. A. Dahm, M. G. Mungal, Proc. Combust. Inst. 20 (1) (1985) 303-310.

[5] G. T. Kalghatgi, Combust. Sci. Tech. 26 (5-6) (1981) 233-239.

[6] C.J. Montgomery, C. R. Kaplan, E. S. Oran, Proc. Combust. Inst. 27(1) (1998)1175-1182.

[7] S. Kumar, P. J. Paul, H. S. Mukunda, Combust. Sci. and Tech. 179(10) (2007) 2219-2253.

[8] N. J. Moore, J. Kribs, K. M. Lyons, Flow Turbulence Combust. 87 (2011)525-536.

[9] M.S. Cha, S.H. Chung, Proc. Combust. Inst. 26(1) (1996)121-128.

[10]W. J. A. Dahm, A. G. Mayman, AIAA J., 28(7) (1990)1157-1162.

[11]W. J. A. Dahm, R.W. Dibble, Proc. Combust. Inst., 22(1988)801-808

[12]J. N. Gomes, J. D. Kribs, K. M. Lyons, J. Combust, 2012(2012), Article ID 218916, doi:10.1155/2012/21891

[13]N. J. Moore, J. L. McCraw, K. M. Lyons, Int. J. React. Syst. 2(2008)811-819.

[14]K. M. Lyons, Prog. Energy Combust. Sci.. 33 (2)(2007)211-231.

[15]S. R. Tieszen, D. W. Stamps, T. J. O'Hern, Combust. Flame, 106(4)(1996)442-466.

[16]K.N. Kim, S.H. Won, S.H. Chung, Proc. Combust. Inst. 31 (2007) 1591-1598.

[17]B.C. Choi, S.H. Chung, Fuel 103 (2013) 956-962.

[18]A. R. Karagozian, Prog. Energy Combust. Sci. 36 (2010) 531-553.

[19]G. T. Kalghatgi, Combust. Flame 52 (1983)91-106.

[20]G. T. Kalghatgi, Combust. Sci. Tech. 26 (5-6) (1981) 241-244.

[21]W. J. Lee, H. D. Shin, Appl. Energy 76 (1-3) (2003) 257-266.

[22]H. Kolla, R.W. Grout, A. Gruber, J.H. Chen, Combust. Flame 159(8) (2012)2755-2766. 
[23]R.W. Grout, A. Gruber, C.S. Yoo, J.H. Chen, Proc. Combust. Inst. 33 (2011) 1629-1637.

[24]R.W. Grout, A. Gruber, H. Kolla, P.T. Bremer, J. C. Bennett, A. Gyulassy, J. H. Chen, J. Fluid. Mech. 706 (2012)351-383.

[25]L.H. Hu, Q. Wang, F. Tang, M. Delichatsios, X.C. Zhang, Fuel 106 (2013)779-786.

[26]X.K. Hu, Y. He, Z. Li, J. Wang, Proc. Combust. Inst. 33 (2) (2011) 2607-2615.

[27]Q. Wang, L.H. Hu, M. Zhang, F. Tang, X.C. Zhang, S.X. Lu, Combust. Flame 161(4) (2014)1125-1130.

[28]L.H. Hu, S. Liu, L. Wu, Combust. Flame 160 (2) (2013) 295-306.

[29]L.W. Kostiuk, A. J. Majeski, P. Poudenx, M. R. Johnson, D. J. Wilson, Proc. Combust. Inst. 28 (2000)553-559.

[30]S. Muppidi and K. Mahesh, J. Fluid Mech. 530 (2005) 81-100.

[31]E. F. Hasselbrink JR, M. G. Mungal, J. Fluid Mech. 443 (2001) 1-25.

[32] S.R. Turns, An Introduction to Combustion, McGraw-hill, New York, 1996.

[33]F.N. Egolfopoulos, C.K. Law, Combust. Flame 80 (1990) 7-16.

[34]E.S. Cho, S.H. Chung, T. K. Oh, Combust. Sci. and Tech. 178(2006)1559-1584.

[35]J. Lee, S. H. Won, S. H. Jin, S. H. Chung, Combust. Flame 135 (2003) 449-462.

[36]E. F. Hasselbrink JR, M. G. Mungal, J. Fluid Mech. 443 (2001) 27-68.

[37]G. Andrews, D. Bradley, Combust. Flame 19 (2) (1972) 275-288.

[38]X. Qin, Y.G. Ju, Proc. Combust. Inst. 30 (1) (2005) 233-240.

[39]X. Wu, Z.H. Huang, X. Wang, C. Jin, C. Tang, L. Wei, C.K. Law, Combust. Flame 158 (3) (2011) $539-546$. 


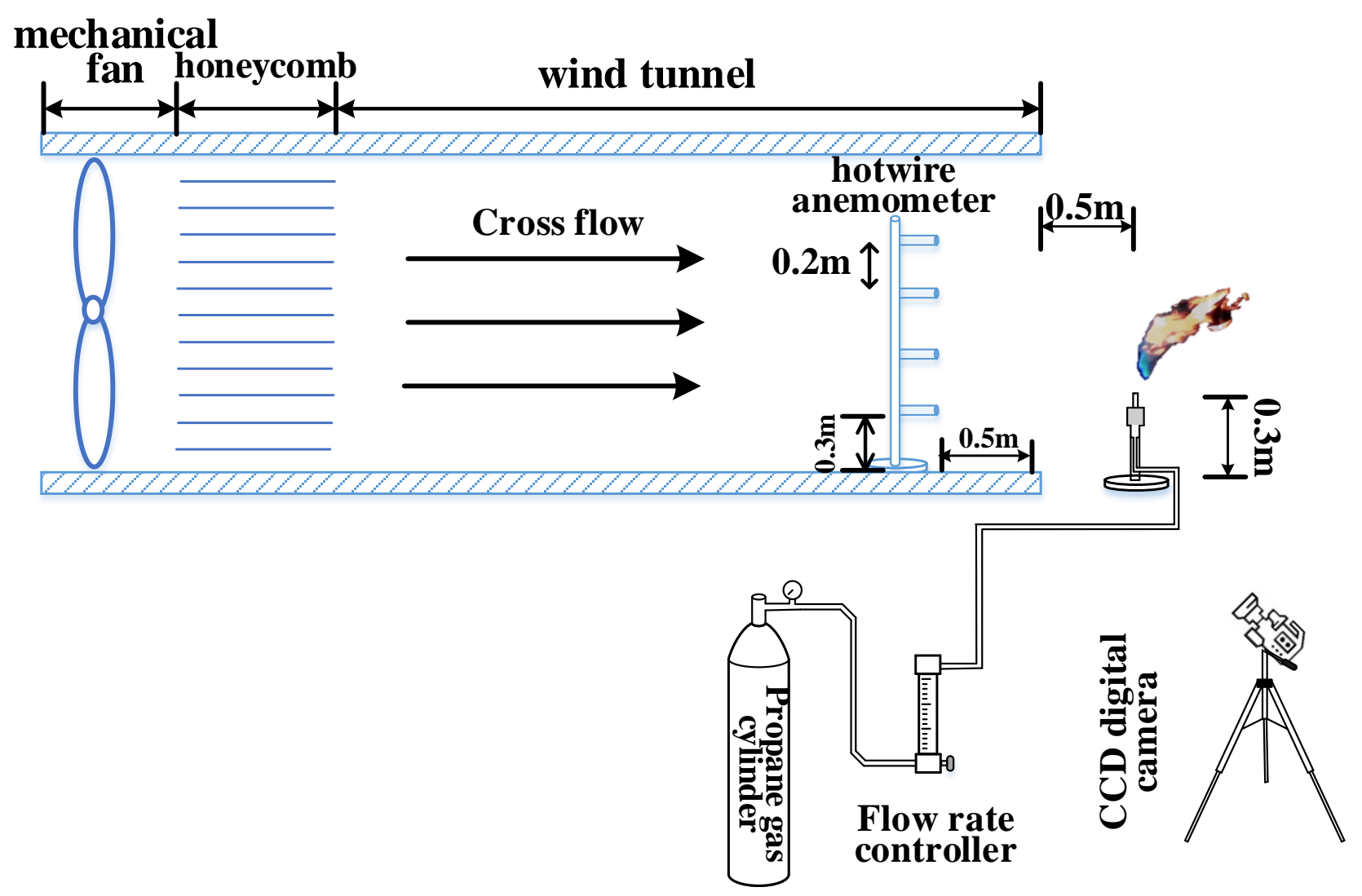

Figure 1. Schematic of the experimental setup. 

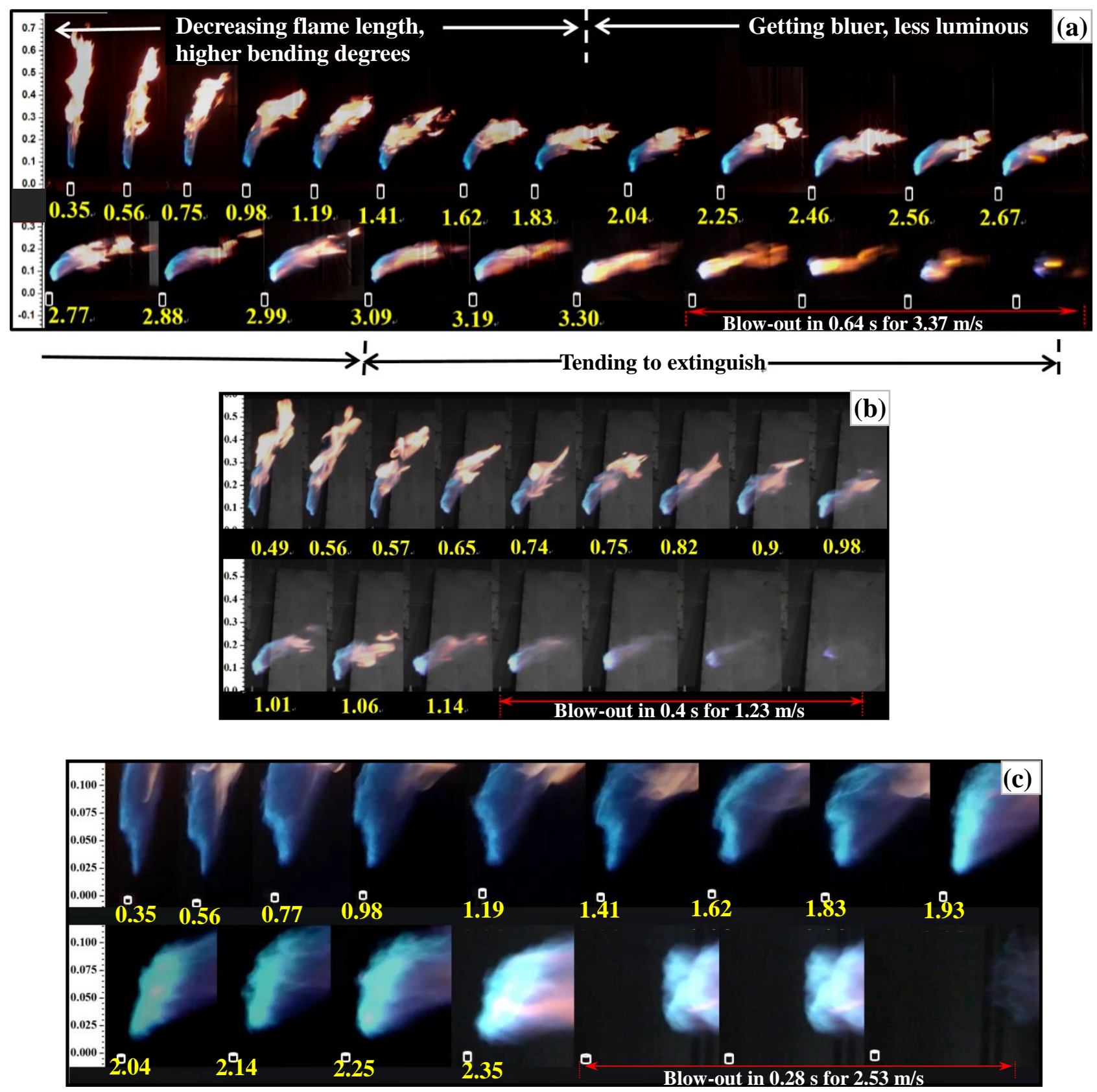

Figure 2: Variation in the flame shape with air speed of the cross flow for $D=3$ mm: (a) $\left(u_{e}[\mathrm{~m} / \mathrm{s}], P_{\infty}[\mathrm{kPa}]\right)=(39.3,100),(\mathrm{b})(16.9,64)$, and $(\mathrm{c})(19.7,100)$. 


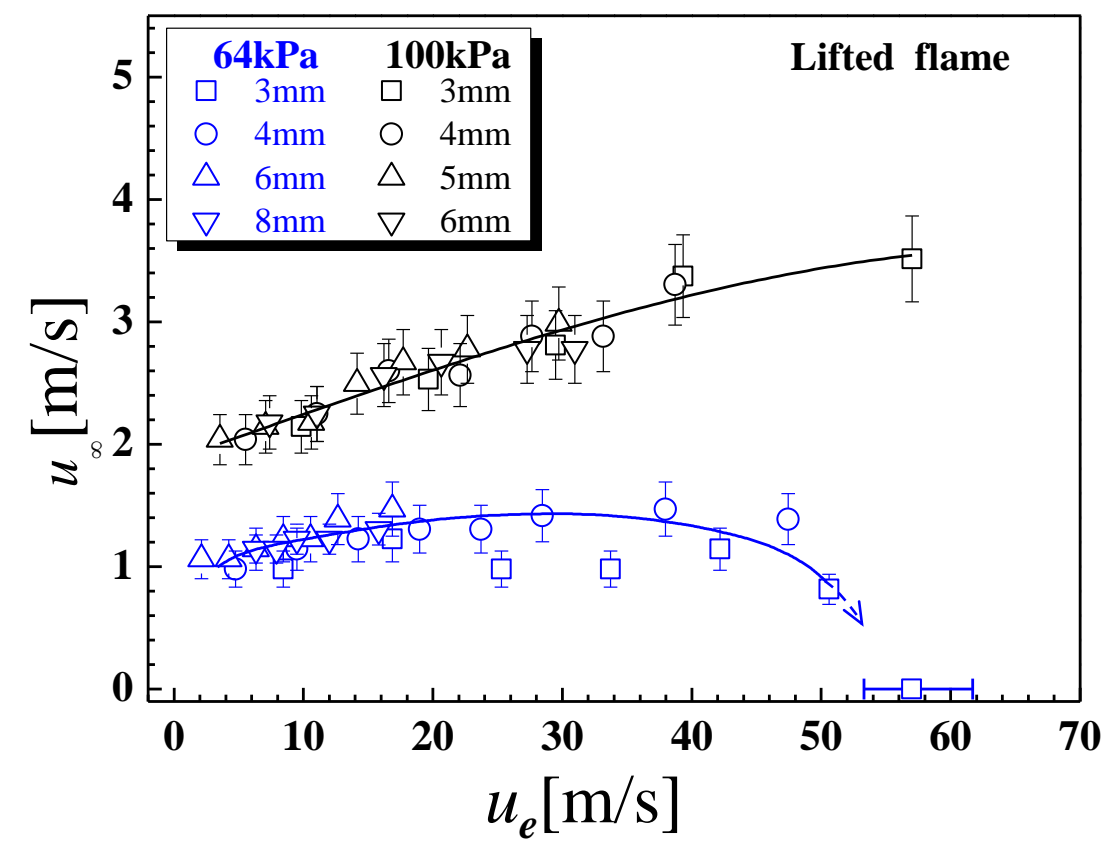

Figure 3: Blow-out limit in terms of the air speed of the cross flow in relation to the fuel jet velocity. 


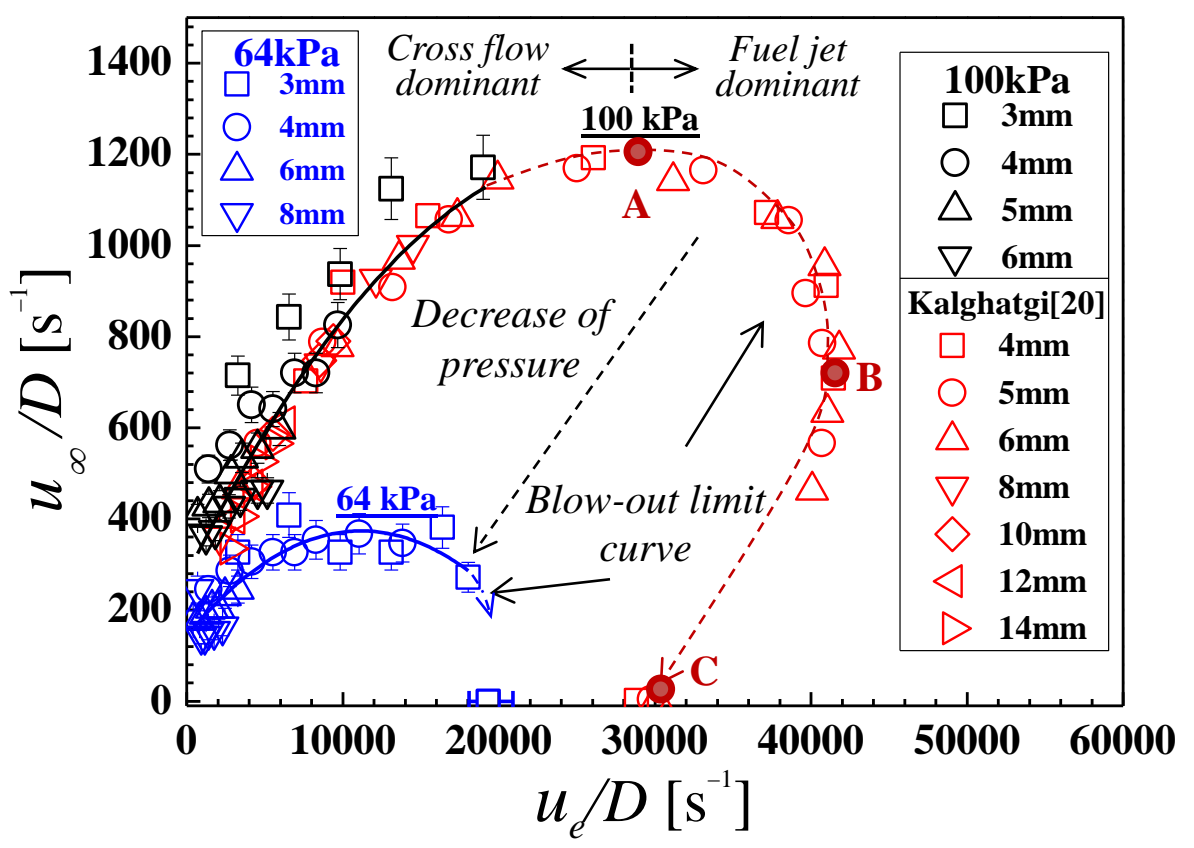

Figure 4: The blow-out limit in terms of the air speed of the cross flow in relation to the fuel jet velocity scaled with nozzle diameter. 


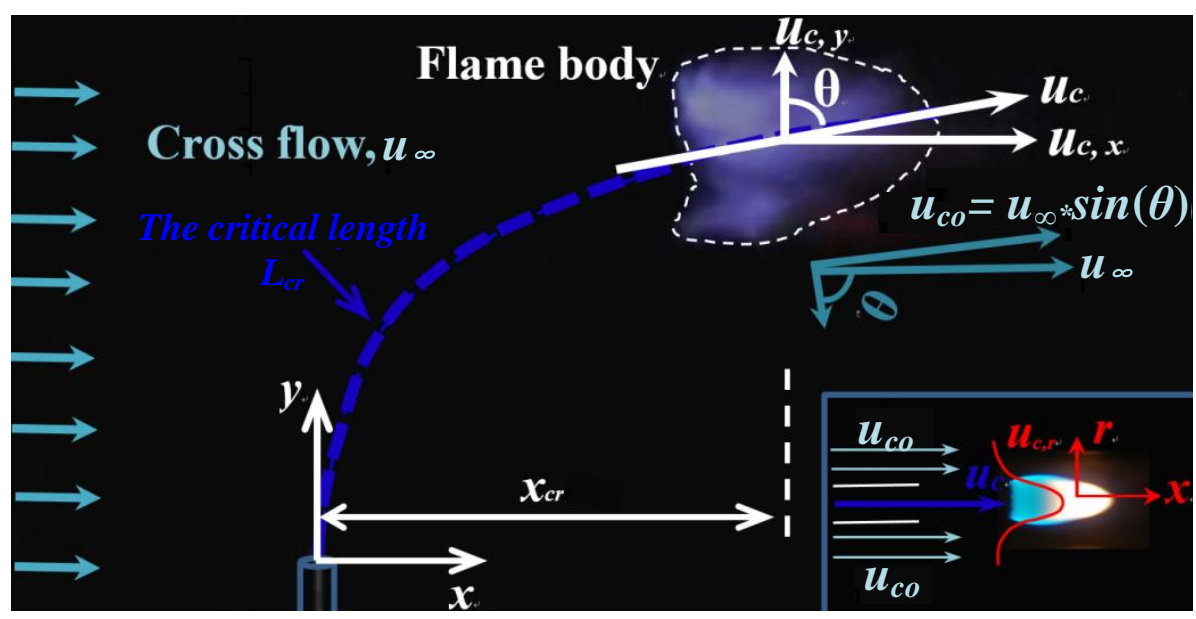

Figure 5: Schematic of the proposed physical model for blow-out in cross flow. 


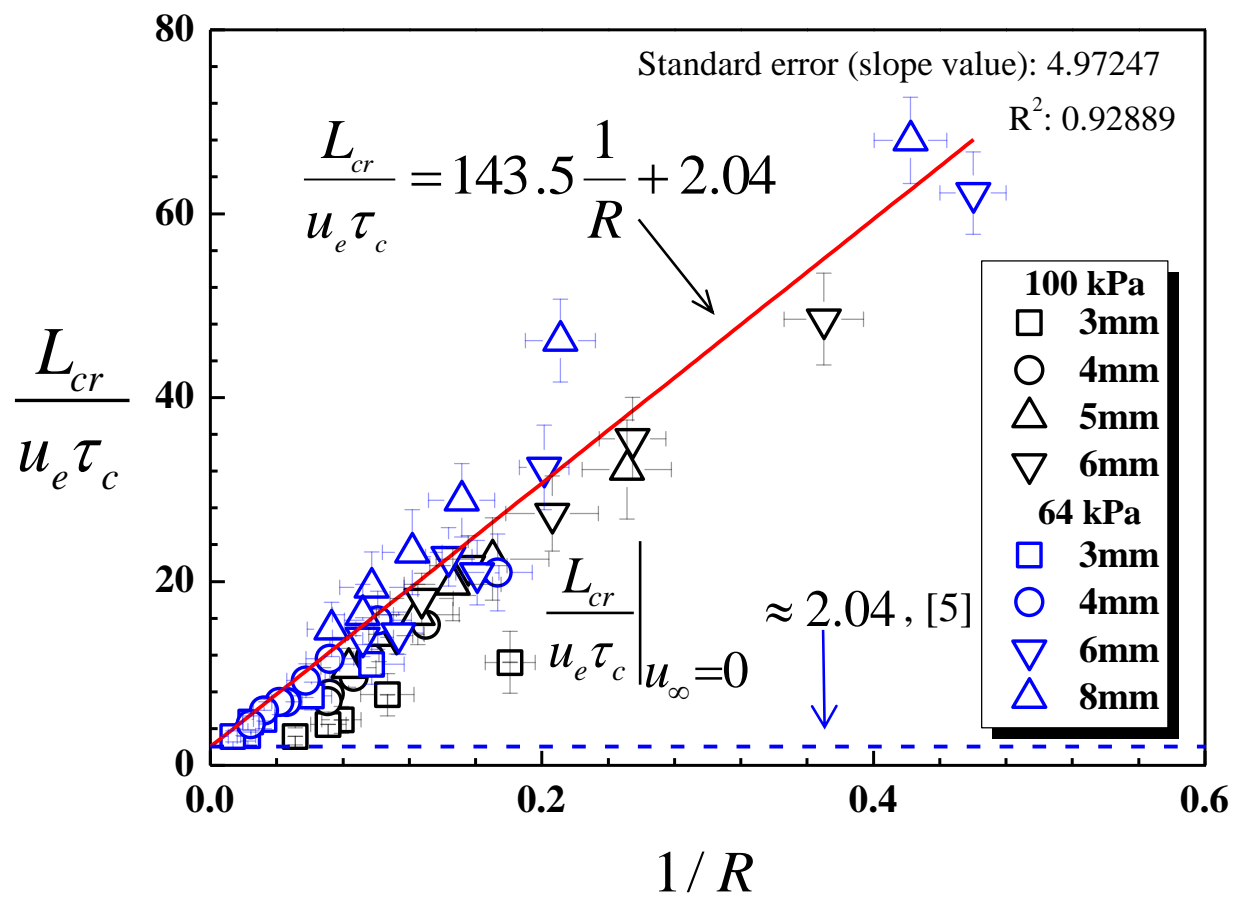

Figure 6: Variation of the critical length of the flame lift-off trajectory in relation to the inverse of the momentum ratio. 


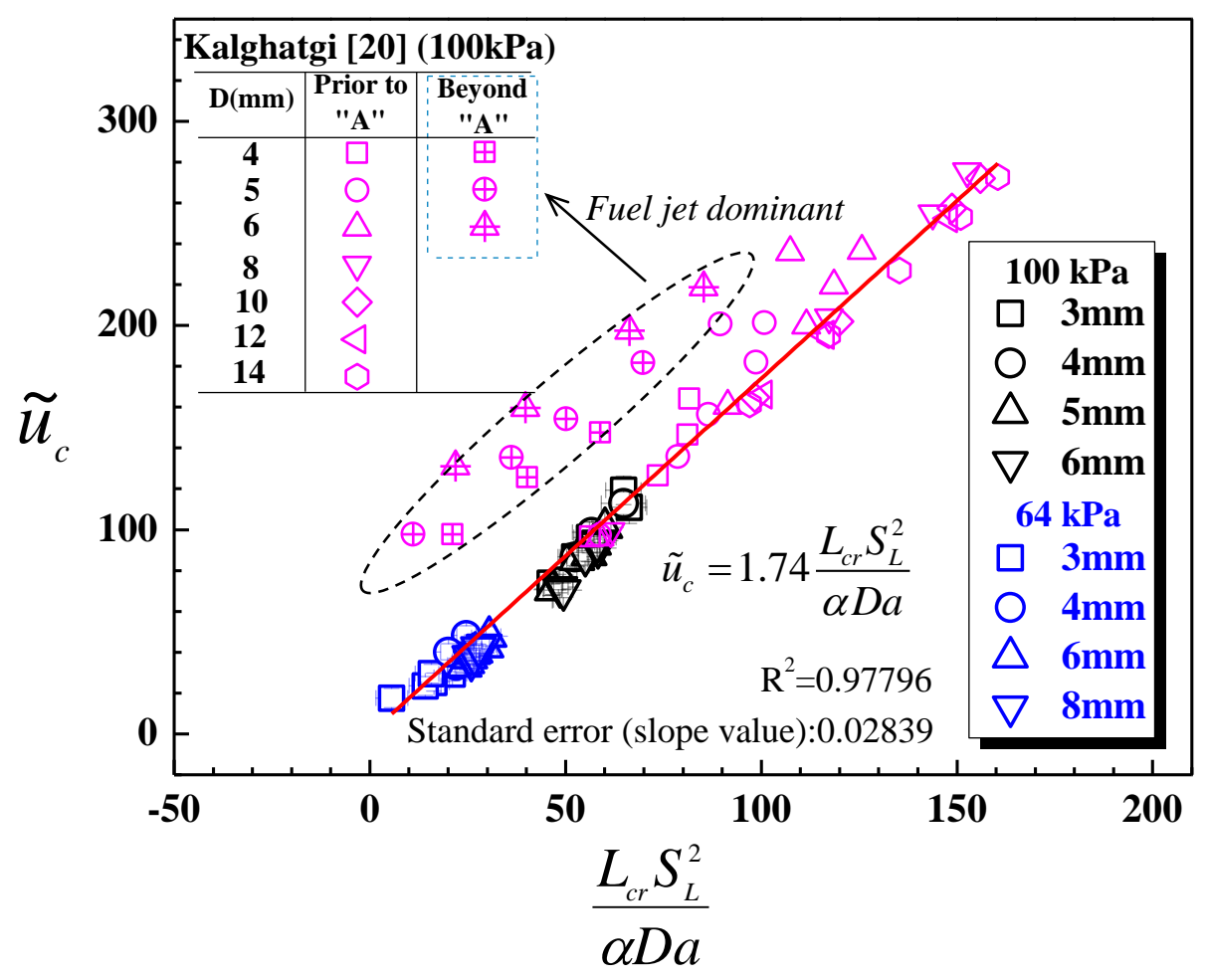

Figure 7: Correlation of the blow-out limit (the critical fuel jet velocity and the air speed of the cross flow) based on the proposed model (Eq. 9). 